\title{
SISTEMA DE ALIMENTAÇÃo GÁS-LÍQUIDO PARA MEDIDAS DE ATIVIDADE CATALÍTICA
}

Oscar W. Perez-Lopez* e Nilson R. Marcílio

Departamento de Engenharia Química, Universidade Federal do Rio Grande do Sul, Rua Luiz Englert s/n, 90040-040 Porto Alegre - RS

Recebido em 28/6/02; aceito em 6/9/02

\begin{abstract}
GAS-LIQUID FEEDING SYSTEM FOR CATALYTIC ACTIVITY MEASUREMENTS. This note has as objective to present the advantages of the use of syringe-type pumps for the feeding of liquid reactants, together with mass flow controllers for gases, instead of the saturators, as it is generally accomplished. Among the advantages, the system with syringe pumps presents a greater flexibility in flow control as well as in composition compared with the system that uses saturator. In addition, the flow of the liquid reactants is known with precision in the syringe pump system.
\end{abstract}

Keywords: liquid feeding; syringe pumps; saturators.

\section{INTRODUÇÃO}

A realização de experimentos para a determinação da atividade catalítica em reatores de laboratório pode visar tanto a avaliação de catalisadores quanto a modelagem cinética de uma reação. Um dos primeiros requisitos para a realização de medidas de atividade catalítica é dispor de um sistema de alimentação de reagentes preciso, confiável e funcional. Quando todos os reagentes estão na fase gasosa a situação é relativamente simples, sendo apenas necessário um equipamento suficientemente preciso para a medição e o controle de vazão dos gases. Entretanto, quando os reagentes a serem alimentados encontram-se na fase líquida (ou estão tanto na fase líquida como gasosa), surgem alguns problemas a serem resolvidos, uma vez que o reagente líquido tem que ser vaporizado utilizando um gás de arraste ou pode ser alimentado independentemente e misturado ao gás de arraste. A solução mais simples no primeiro caso - e a mais utilizada - é através do uso de um saturador. Este sistema, no entanto, apresenta algumas restrições, como será visto mais adiante.

O objetivo deste artigo é descrever uma maneira prática e flexível de alimentar simultaneamente reagentes líquidos e gasosos para medidas de atividade catalítica utilizando bombas dosadoras e controladores de fluxo, respectivamente.

\section{ALIMENTAÇÃO DE REAGENTES LÍQUIDOS VIA SATURADOR}

Diversos trabalhos encontrados na literatura evidenciam que o sistema mais utilizado, ou o mais preferido, para a alimentação de reagentes líquidos é através de um saturador (veja-se por exemplo os Anais do $11^{\circ}$ Congresso Brasileiro de Catálise). Neste sistema, o reagente é colocado no saturador onde borbulha-se o gás de arraste. O saturador é uma peça cilíndrica confeccionada em vidro. Na parte superior localizam-se a entrada para o gás de arraste e a saída do gás saturado. Na parte inferior coloca-se uma placa de vidro sinterizado para facilitar a mistura do gás com o líquido. Os detalhes desta peça podem ser observados na Figura 1. O saturador pode ser confeccionado também com duas peças em série, para aumentar a eficiência da saturação, assumindo um formato em " $\mathrm{H}$ ".

*e-mail: perez@enq.ufrgs.br

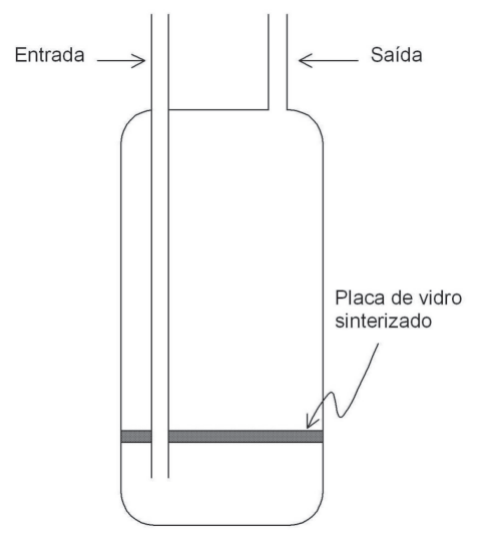

Figura 1. Saturador utilizado para alimentação de reagente líquido

Uma desvantagem deste sistema reside em que a quantidade de reagente que está sendo alimentado é obtida apenas indiretamente. Para isso são necessários dados da vazão do gás de arraste utilizado, a temperatura e a pressão no saturador. Com estes dados utiliza-se uma equação adequada para calcular a pressão de vapor do reagente (em função da temperatura) e estima-se a vazão de reagente, considerando-se que a saturação seja completa. Deve ser notado também que este sistema de alimentação requer aquecimento da linha que conduz a mistura reacional até o reator, para que não ocorra a condensação do reagente. A quantidade de reagente a ser alimentada pode ser controlada variando-se a vazão do gás de arraste e a temperatura do saturador, já que este último geralmente fica imerso em um banho termostatizado. A necessidade de um banho termostatizado acaba aumentando significativamente o custo deste sistema.

Uma outra grande desvantagem do sistema de alimentação com saturador é a baixa flexibilidade em termos de vazão e composição. A baixa flexibilidade deve-se ao fato da vazão de reagente estar associada ao gás de arraste. A restrição em termos de composição ocorre, por exemplo, quando é necessário trocar a composição da mistura reacional com uma certa freqüência (quando se tem dois ou mais reagentes líquidos). Para isso teria que ser retirado o reagente do saturador, lavar e carregar com a mistura líquida preparada e, por 
último, purgar o sistema. Uma freqüente troca da composição de alimentação pode ser necessária, por exemplo, para a realização de um trabalho de modelagem cinética.

\section{ALIMENTAÇÃO DE REAGENTES LÍQUIDOS COM BOMBAS DOSADORAS TIPO SERINGA}

A escolha de uma bomba dosadora para a alimentação de reagentes líquidos, visando a realização de medidas de atividade catalítica deve basear-se, fundamentalmente, numa vazão precisa e uniforme e, portanto, livre de oscilações. Este requisito não é satisfeito pelas bombas de deslocamento positivo ou tipo pistão que proporcionam um fluxo por pulsos sendo, portanto, necessário o uso de amortecedores de pulsação para eliminar as oscilações geradas pelo pistão da bomba, o que nem sempre é possível de se conseguir.

As bombas tipo seringa satisfazem estes requisitos e, além disso, apresentam vantagens pois, além de proporcionarem uma vazão livre de pulsações, têm alta precisão e uma grande flexibilidade na vazão fornecida. Os únicos cuidados a serem tomados são uma escolha adequada do volume da seringa a ser utilizada, a pressão máxima a ser utilizada e conexões adequadas para conduzir o reagente da seringa até a entrada do reator.

Para a escolha do volume da seringa a ser utilizada na bomba dosadora, provavelmente a tendência do usuário seria a de garantir a maior autonomia possível e, portanto, a escolha recairia numa seringa com o maior volume possível (as seringas fornecidas pelos fabricantes, compatíveis com a bomba dosadora, podem ter uma capacidade de até $100 \mathrm{ml}$ ). Entretanto, a escolha necessita ser mais cuidadosa, já que se deve lembrar que estas bombas dosadoras proporcionam uma força linear constante (por exemplo $20 \mathrm{lb}_{\mathrm{f}}$ ). Portanto, a força linear da bomba deverá ser maior que a força oposta ao deslocamento, devida à pressão no reator e à forca de atrito no êmbolo.

A pressão exercida pela bomba pode ser estimada dividindo-se a força exercida pela bomba (fornecida pelo fabricante) pela área do êmbolo da seringa. Na Tabela 1 ilustram-se estes cálculos com diferentes tamanhos de seringas, para uma bomba que proporciona uma força linear de $20 \mathrm{lb}_{\mathrm{f}}$ e considerando-se uma pressão manométrica no reator de 15 psi (aproximadamente $1 \mathrm{~atm}$ ).

Tabela 1. Cálculos para seringas Hamilton com diferentes volumes $\left(\mathrm{F}_{\text {bomba }}=201 \mathrm{~b}_{\mathrm{f}}\right)$

\begin{tabular}{ccccc}
\hline $\begin{array}{c}\text { Volume } \\
(\mathrm{ml})\end{array}$ & $\begin{array}{c}\text { Comprimento } \\
(\mathrm{cm})\end{array}$ & $\begin{array}{c}\text { Área } \\
\left(\mathrm{in}^{2}\right)\end{array}$ & $\begin{array}{c}\text { P reator } \\
(\mathrm{psi})\end{array}$ & $\begin{array}{c}\text { P bomba } \\
(\mathrm{psi})\end{array}$ \\
\hline 0,5 & 6 & 0,013 & 15 & 1548 \\
2,5 & 6 & 0,065 & 15 & 310 \\
10 & 6 & 0,258 & 15 & 77,4 \\
25 & 6 & 0,646 & 15 & 31,0 \\
50 & 6 & 1,292 & 15 & 15,5 \\
\hline
\end{tabular}

Nota-se que, conforme aumenta o volume da seringa diminui a pressão exercida pela bomba, de modo que para uma seringa de 50 $\mathrm{ml}$ a pressão no reator é equivalente à pressão imposta pela bomba no êmbolo. Neste caso, a força linear da bomba seria insuficiente para vencer a resistência exercida pela pressão no reator, já que deve ser considerada ainda a força de atrito entre o êmbolo e a seringa, que é proporcional ao diâmetro do êmbolo, ou seja ao volume da seringa. Portanto, nesta situação seria descartado o uso da seringa de $50 \mathrm{ml}$ adotando-se, por conseguinte, seringas com volumes de $25 \mathrm{ml}$ ou menores. $\mathrm{O}$ volume da seringa deverá ser proporcional à vazão de reagente a ser utilizada, ou seja quanto menor a vazão, menor o tamanho da seringa.

No caso de haver a necessidade do uso de dois ou mais reagentes líquidos, cada reagente deverá ser alimentado através de bombas dosadoras independentes. Desta maneira é possível conseguir uma grande flexibilidade na composição da alimentação dos reagentes líquidos, bastando apenas ajustar a vazão de cada reagente para obter a composição requerida. Além disso, pode-se alterar a vazão total mantendo-se uma dada composição. Cabe destacar também que neste caso a vazão dos reagentes líquidos é completamente independente da vazão dos gases utilizados sendo, portanto, possível variar a pressão parcial de todos os componentes, ao contrário do sistema que utiliza saturador.

Um cuidado a ser tomado com a bomba tipo seringa é evitar a possibilidade de qualquer vazamento. Para isso deve-se manter uma perfeita vedação na passagem do reagente da seringa até o reator. Uma vez que as seringas disponíveis no mercado são geralmente de vidro, é necessário utilizar materiais compatíveis para fazer a transferência do reagente contido na seringa. Sendo assim, é recomendável que a seringa tenha a extremidade (na saída do reagente) numa configuração tipo "luer lock", que é um sistema de conexão por travamento a rosca, que precisa apenas de um aperto manual. As outras partes constituintes também deverão ter este mesmo tipo de conexão, combinando-se o tipo "macho" com o tipo "fêmea".

Para conduzir o reagente da seringa ao reator podem ser utilizadas mangueiras de teflon ou polipropileno (por exemplo com diâmetro de 1/8"), sendo esta última opção a mais econômica. Deve-se evitar o uso de mangueiras de silicone, por serem suscetíveis à permeação por alguns compostos orgânicos (por exemplo álcoois e solventes). Além disso são necessárias conexões tipo "female luer/tube" (Cole Parmer PN 06359-27, por exemplo) a serem colocadas nas extremidades da mangueira e um conector em teflon tipo macho/macho (Hamilton, PN 86511) para ligar a mangueira a uma agulha em aço inox, a qual introduzirá o reagente líquido no reator. Com o uso destas conexões é possível obter uma perfeita vedação, sendo também fácil a montagem/ desmontagem (por exemplo para carregar o reagente). Além disso, como todos os materiais são transparentes isto permite detectar uma eventual formação de bolhas no reagente, durante o percurso até o reator, eliminando-se assim uma possível fonte de erro.

A faixa de vazão que pode ser obtida com uma dada seringa é muito ampla. Por exemplo para uma seringa de $10 \mathrm{ml}$ é possível obter vazões desde 0,2 até $125 \mathrm{ml} / \mathrm{h}$, o que seria praticamente impossível com outro tipo de bomba, e muito menos com um saturador.

\section{REAGENTES GASOSOS}

Para a alimentação de gases (reagentes ou inertes) a opção mais recomendada é o uso de controladores de fluxo mássico disponíveis no mercado. Embora seu custo seja um tanto elevado, a precisão obtida para as vazões a serem controladas justifica o investimento. $\mathrm{O}$ único cuidado na compra é definir o intervalo de vazão e o gás a ser utilizado. Alguns fabricantes fornecem calibração para o uso com diferentes gases.

Para conduzir os gases do controlador ao reator, deve-se evitar o uso de mangueiras de borracha ou silicone pois são altamente permeáveis a gases, principalmente ao hidrogênio, para tanto deve ser preferido tubo em aço inox limpo e sem costura. Além disso é recomendável também instalar "em linha", antes da entrada dos gases nos controladores de fluxo, um filtro de aço inox sinterizado para impedir a entrada de partículas sólidas nos controladores. Estes filtros são removíveis (pode-se trocar o filtro interno da peça) e podem ser encontrados em diferentes "mesh", desde $0,5 \mu \mathrm{m}$. 


\section{CONEXÃO E ENTRADA NO REATOR}

Para a admissão dos reagentes ao reator, é necessária uma peça metálica (em aço inox) que disponha de uma entrada para os reagentes líquidos e outra entrada para os reagentes gasosos e, além disso, que faça simultaneamente a conexão com o reator. Neste caso a conexão será do tipo metal-vidro, já que está sendo considerado o uso de um reator de vidro ou quartzo. Dificilmente será possível encontrar no mercado uma peça com estas características, portanto será necessário mandar confeccionar uma.

Na Figura 2 apresentam-se os detalhes desta conexão. Para a entrada dos gases foi soldada, lateralmente, uma peça de tubo de aço inox $1 / 8$ " por onde são admitidos os gases procedentes dos controladores de fluxo. A admissão dos reagentes líquidos é feita na parte superior desta conexão tendo-se implementado um sistema similar aos injetores dos cromatógrafos a gás, utilizando-se para isso um septo de teflon onde podem ser inseridas as agulhas das seringas. A parte inferior desta peça permite realizar a conexão com o reator. Como trata-se de uma conexão metal-vidro, utilizou-se um sistema de vedação com anilha e O-ring.

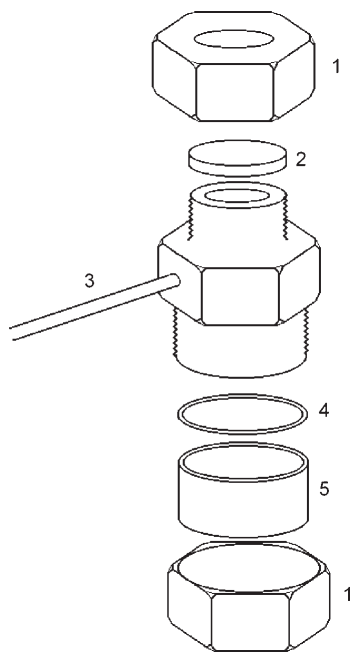

Figura 2. Detalhes da conexão alimentação/reator: 1) porca, 2) septo de teflon, 3) entrada para gases, 4) O-ring, 5) anilha metálica

Por outro lado, uma vez que os reagentes líquidos têm que chegar completamente vaporizados ao leito catalítico, foi implementada uma seção de entrada no reator, conforme apresenta-se na Figura 3, a qual tem duas finalidades: a primeira, visa efetuar o pré-aquecimento da mistura reacional in loco de modo que esta chegue ao leito catalítico previamente aquecida e vaporizada, eliminando-se assim a necessidade de um vaporizador externo. A outra finalidade é a de proporcionar uma seção de entrada reta, de modo que os reagentes líquidos possam escoar uniformemente até ocorrer a completa vaporização. Caso contrário, como as vazões são geralmente baixas, poderia ocorrer a acumulação do reagente líquido (tendência a formar gotas), resultando em variações nas medidas de atividade catalítica. Além disso, para facilitar a mistura dos reagentes nesta seção de entrada sugere-se o uso de esferas de vidro.

Na Figura 4 tem-se uma tomada fotográfica ilustrando a seção de entrada de um equipamento dotado com duas bombas dosadoras para líquidos e dois controladores de fluxo (não visíveis). Observa-

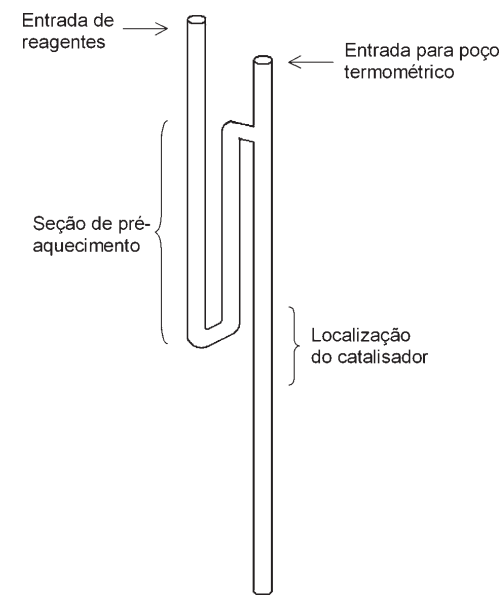

Figura 3. Reator tubular implementado com seção de pré-aquecimento

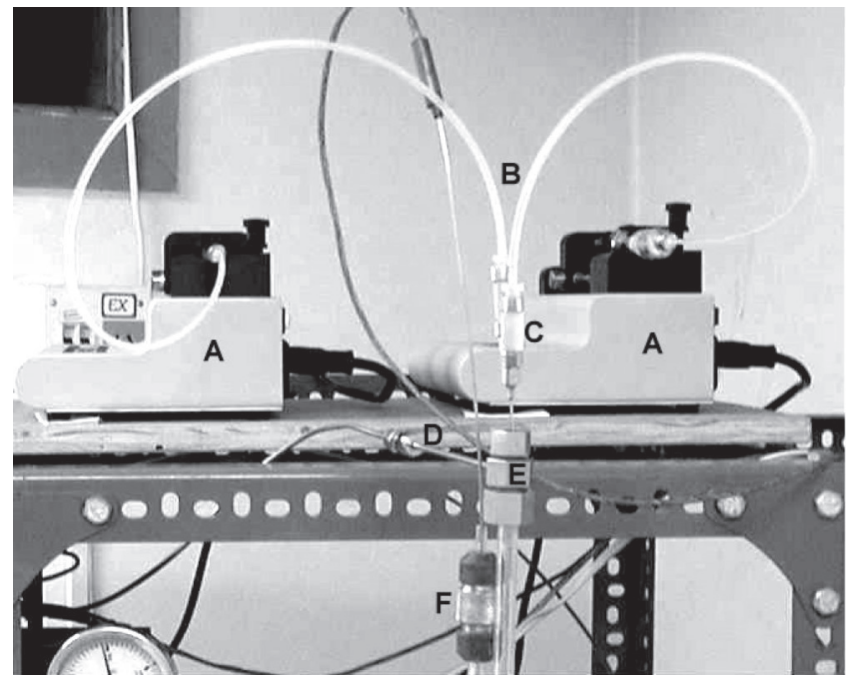

Figura 4. Detalhe da seção de alimentação: A) bomba dosadora tipo seringa, B) mangueiras, C) conexão mangueira/agulha, D) entrada de gases, E) conexão alimentação/reator, $F$ ) conexão entre poço termométrico e reator

se a entrada dos reagentes líquidos através das agulhas e os gases sendo alimentados através do tubo lateral em aço inox.

\section{VANTAGENS DA BOMBA TIPO SERINGA}

As principais vantagens de um sistema com bombas tipo seringa são grande flexibilidade na vazão proporcionada, fornecer uma vazão livre de oscilações e ter a capacidade de proporcionar vazões extremamente baixas. Além disso, para a alimentação de misturas, através do uso de bombas independentes para cada reagente puro, pode-se obter a composição desejada para diferentes tempos de residência.

\section{AGRADECIMENTOS}

Os autores agradecem à Fundação de Amparo à Pesquisa do Estado de Rio Grande do Sul (FAPERGS) pelo apoio financeiro. 